\title{
Simulative Comparison of Mobile Air-Conditioning Concepts for Mechanical and Electrical Driven Systems
}

\author{
Arnim von Manstein ${ }^{1}$ Dirk Limperich $^{1} \quad$ Shivakumar Banakar $^{2}$ \\ ${ }^{1}$ Daimler AG, Germany, \{arnim.von_manstein, dirk.limperich\}@ daimler.com \\ ${ }^{2}$ Mercedes Benz R \& D India Pvt. Ltd., India, Shivakumar. banakar@daimler. com
}

\begin{abstract}
Ever increasing energy demand and the stringent emission norms have resulted in the need for developing more efficient automotive systems. Fuel economy and emission targets are the two important driving factors in the development of an automobile. Efficiency of a Mobile Air-Conditioning system (MAC) has a considerable impact on the fuel economy of an automobile. This study involves simulative comparison of MAC concepts for mechanical \& electrical driven systems. System models are developed for MAC concepts using Dymola simulation tool. Drive cycles considered in this study correspond to the real time driving scenarios and ambient conditions. From this study the conclusions are drawn about the most efficient ways to reach the thermal comfort for the passenger cabin in an automobile.
\end{abstract}

Keywords: Energy Efficiency; MAC; HVAC; LV; HV; MHEV; PHEV; BEV; Compressor; Dymola.

\section{Introduction}

MAC systems were considered to be an optional equipment in the past for the automobiles. Nowadays they have become an integral part of all the cars that are produced. In the recent time momentum has gained for the development of hybrid \& electric vehicles which means that vapor compression refrigeration systems will become a necessity for passenger cabin cooling as well as battery cooling. The UN estimated the sale of more than one billion cars with MAC system in 2015 which has resulted in 2.3 gigatons of carbon dioxide adding into the environment (Lemke et al. 2011). In order to reduce the world wide emission caused by automobiles there are two ways. One is to reduce the direct emissions of cars. For example implementing stringent emission norms, use of alternative powertrain concepts, reducing weight by replacing heavy cast iron components are very simple and effective methods (Slattery et al. 2010). The second way would be to reduce the indirect emissions by changing for example refrigerants of the refrigeration cycle. Especially for the second way the European Union set in the directive 2006/40/EC the way to reduce the Global Warming Potential (GWP) of refrigerants. It is set that from January 2017 only refrigerants with a GWP of lower than 150 are allowed to be sold in Europe (Europäische Union 6/14/2006). In order to fulfill this directive there are two alternatives, one is R1234yf (2, 3, 3, 3-Tetrafluorpropen) with a GWP of 4 and the other is R744 (CO2) with a GWP of 1.

The refrigerant loop in a MAC system consists of an evaporator, compressor, condenser and expansion valve. The low temperature, low pressure vapor is compressed by a compressor to a high temperature and high pressure vapor. This vapor is condensed into high pressure liquid in the condenser, by rejecting heat to a low temperature ambient air and then passes through the expansion valve. Here, the high pressure liquid is throttled down to a low pressure liquid and passed on to an evaporator, where it absorbs heat from the cabin air and vaporizes into a low pressure vapor. Then it reaches compressor suction line and the cycle repeats. In order to increase the efficiency, Daimler AG, Germany, introduced at early stages for example internal heat exchanger (IHX). There the refrigerant is subcooled after it exits the condenser. Therefore you can reach lower temperatures after expansion to increase cooling capacity on the one hand and ensure compressor safety on the other side due to its superheating effect after the refrigerant exits the evaporator. By ensuring superheat at the compressor suction, we can eliminate liquid lock.

A key component of a MAC system is the compressor. This refrigerant compressor is driven in state of the art automobiles with a belt drive directly from an Internal Combustion Engine (ICE). With hybrid powertrain such as Mild Hybrid Electric Vehicle (MHEV), Plug-in Hybrid Electric Vehicle (PHEV) and Battery Electric Vehicle (BEV), the compressor is driven by an electric motor via the necessary voltage level. Especially for MHEV there are changes in the automotive industry to reduce this voltage level limit up to $60 \mathrm{~V}$. The further reduction in voltage level with electrification of the powertrain is known and also the new voltage level already described in detail (Coppin, Potteau 2015).

With this electrification and with the implementation of stringent emission norms to reduce emission of carbon dioxide, have resulted in the tremendous changes for MAC. 


\section{Experimental Procedure}

System simulation techniques play a very important role in the development and evaluation of various concepts for MAC system. So far the simulation predictions were mainly used to determine whether the designed MAC system is able to achieve thermal comfort for the customer at certain boundary conditions.

Going a step further the car manufacturers are interested in studying the system behavior under real time operating conditions of the customer. For sure testing with prototypes is very important testing set up, but lot of what if scenarios can be addressed through simulation studies in the early stages of concept development and concept evaluations.

In this study we will limit ourselves to a comparison of MAC system driven by a mechanical compressor and an electrical compressor. Because, already there are large number of scientific papers that discuss the overall efficiency of ICE and hybrid powertrain, such as (Carpetis 2000). These concepts are evaluated using Dymola simulation tool. In general this study will result in an overall discussion about what is the most efficient way to reach thermal comfort in an automotive cabin.

In our special use case we evaluate two types of compressor that come along in automotive application:

1. Regular mechanical compressor driven by belt drive

2. HV electrical compressor with a voltage level around $400 \mathrm{~V}$

Fortunately, there are several reports about World's climate conditions such as the FAT 224. In order to reduce complexity we just take MAC system operation into consideration and will provide data for the ambient air temperature of $22^{\circ} \mathrm{C}, 29^{\circ} \mathrm{C}$ and $35^{\circ} \mathrm{C}$.

As mentioned, these systems are operated by customers in different ambient and driving conditions. Most severe conditions for MAC systems are higher ambient temperatures at low car speed.

Daimler AG has selected one drive cycle (MBVT), which was created using the real time data from vehicles operating in various driving scenarios and ambient conditions all over the world.

The MBVT is a mixed drive cycle with $\approx 50 \%$ inner city driving, $\approx 35 \%$ interstate and $\approx 15 \%$ highway (Autobahn) profile. Additional parameters in the drive cycle include time/speed gradients, acceleration, deceleration and the pitch. The stop phases are calculated to be roughly about 4.5 mins.

The MAC system investigated in this study is based on a series production S-Class system which is operated in both systems with a hydrofluoroolefin refrigerant (such as R134a/R1234yf). This set up is described in detail in Section 3.

\section{System Description and Simulation Model}

The vapor compression refrigeration system components configurations that we have used for investigation in our study corresponds to the series production S-Class car. Table 1 describes geometrical parameters of all components used in the system.

Table 1. Component details \& geometrical parameters

\begin{tabular}{|c|c|c|c|}
\hline Component & Description & \multicolumn{2}{|c|}{ Geometry } \\
\hline \multirow{5}{*}{ Condenser } & \multirow{5}{*}{$\begin{array}{l}\text { Cross flow, } \\
\text { Fin \& Tube } \\
\text { heat } \\
\text { exchanger } \\
\text { with } 2 \text { layers }\end{array}$} & $\begin{array}{l}\text { Height } \\
(\mathrm{mm})\end{array}$ & 453.10 \\
\hline & & $\begin{array}{l}\text { Width } \\
(\mathrm{mm})\end{array}$ & 640 \\
\hline & & $\begin{array}{l}\text { Depth } \\
(\mathrm{mm})\end{array}$ & 12 \\
\hline & & HTA $\left(\mathrm{m}^{2}\right)$ & 2.0158 \\
\hline & & $\begin{array}{l}\text { Volume } \\
\left(\mathrm{m}^{3}\right)\end{array}$ & $\begin{array}{l}5.552 \mathrm{E}- \\
4\end{array}$ \\
\hline \multirow{5}{*}{ Evaporator } & \multirow{5}{*}{$\begin{array}{l}\text { Air cooled, } \\
\text { Cross flow, } \\
\text { Fin \& Tube } \\
\text { heat } \\
\text { exchanger }\end{array}$} & $\begin{array}{l}\text { Height } \\
(\mathrm{mm})\end{array}$ & 223 \\
\hline & & $\begin{array}{l}\text { Width } \\
(\mathrm{mm})\end{array}$ & 303 \\
\hline & & $\begin{array}{l}\text { Depth } \\
(\mathrm{mm})\end{array}$ & 50 \\
\hline & & HTA $\left(m^{2}\right)$ & 1.199 \\
\hline & & $\begin{array}{l}\text { Volume } \\
\left(\mathrm{m}^{3}\right)\end{array}$ & $\begin{array}{l}0.0011 \\
78 \\
\end{array}$ \\
\hline \multirow{2}{*}{$\begin{array}{l}\text { Internal } \\
\text { Heat } \\
\text { Exchanger }\end{array}$} & \multirow{2}{*}{$\begin{array}{l}\text { Concentric } \\
\text { tube in tube } \\
\text { heat } \\
\text { exchanger }\end{array}$} & $\begin{array}{l}\text { Length } \\
(\mathrm{mm})\end{array}$ & 498 \\
\hline & & $\operatorname{HTA}\left(\mathrm{m}^{2}\right)$ & $\begin{array}{l}0.0837 \\
2 \\
\end{array}$ \\
\hline $\begin{array}{l}\text { Expansion } \\
\text { Valve }\end{array}$ & $\begin{array}{l}\text { Thermal } \\
\text { Expansion } \\
\text { Valve with } \\
\text { superheat } \\
\text { feedback }\end{array}$ & $\begin{array}{l}\text { Capacity } \\
\text { (ton) }\end{array}$ & 2.0 \\
\hline $\begin{array}{l}\text { Compressor } \\
1\end{array}$ & $\begin{array}{l}\text { Swash plate } \\
\text { variable } \\
\text { displacement } \\
\text { compressor } \\
\end{array}$ & $\begin{array}{l}\text { Capacity } \\
\text { (cc) }\end{array}$ & 170.0 \\
\hline $\begin{array}{l}\text { Compressor } \\
2\end{array}$ & $\begin{array}{l}\text { Scroll } \\
\text { compressor }\end{array}$ & $\begin{array}{l}\text { Capacity } \\
\text { (cc) }\end{array}$ & 33 \\
\hline
\end{tabular}

Simulation models of the components of refrigerant loop are developed using a multi-engineering dynamic simulation tool Dymola (version 2015 FD01) and Airconditioning Library (version 1.9). The snapshot of the system model developed in Dymola is as shown in Figure 2. In the first step heat exchangers like Condenser, Evaporator \& IHX (Internal Heat Exchanger) are modelled using the templates from airconditioning library and geometrical data. The developed heat exchanger models are then calibrated and validated using the calibration toolbox within 
Dymola and experimental data from suppliers. The compressor model is as described below.

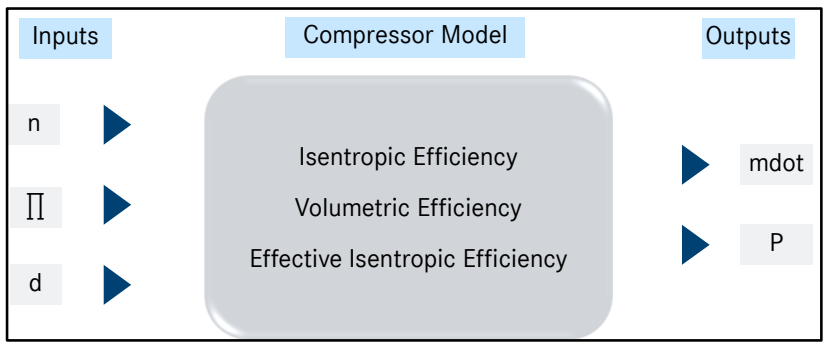

Figure 1. Compressor model variables

Where,

$\mathrm{n}=$ Compressor speed

$\pi=$ Compressor pressure ratio

$\mathrm{d}=$ Relative displacement

mdot $=$ Refrigerant mass flow rate through compressor $\mathrm{P}=$ Compressor power consumption

Efficiencies of the compressor i.e., isentropic efficiency, volumetric efficiency and effective isentropic efficiency are modeled as a function of compressor speed, relative displacement and pressure ratio. Correlations for the compressor efficiencies are developed using the measured data from the supplier. Range of the compressor measurement data used for the modelling is shown in Table 2. The standard deviations in isentropic efficiency \& volumetric efficiency models are found to be $4.81 \% \& 2.9 \%$ respectively. Compressor performance parameters like mass flow rate, power consumption and compressor discharge temperature are computed using these efficiency values.

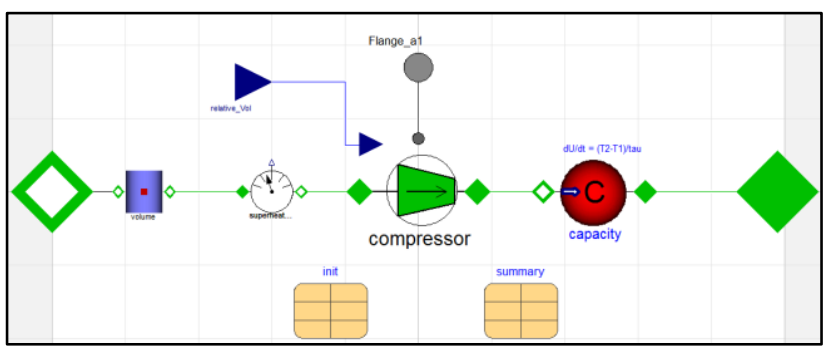

Figure 2. Representation of a compressor model developed in Dymola.

Table 2. Details of the compressor measured data used for modelling.

\begin{tabular}{|l|l|l|l|}
\hline Parameters & $\pi$ & $\mathrm{n}(\mathrm{rpm})$ & $\mathrm{d}$ \\
\hline Range & 2.5 to 8.4 & 700 to 8000 & 0.35 to 1.0 \\
\hline
\end{tabular}

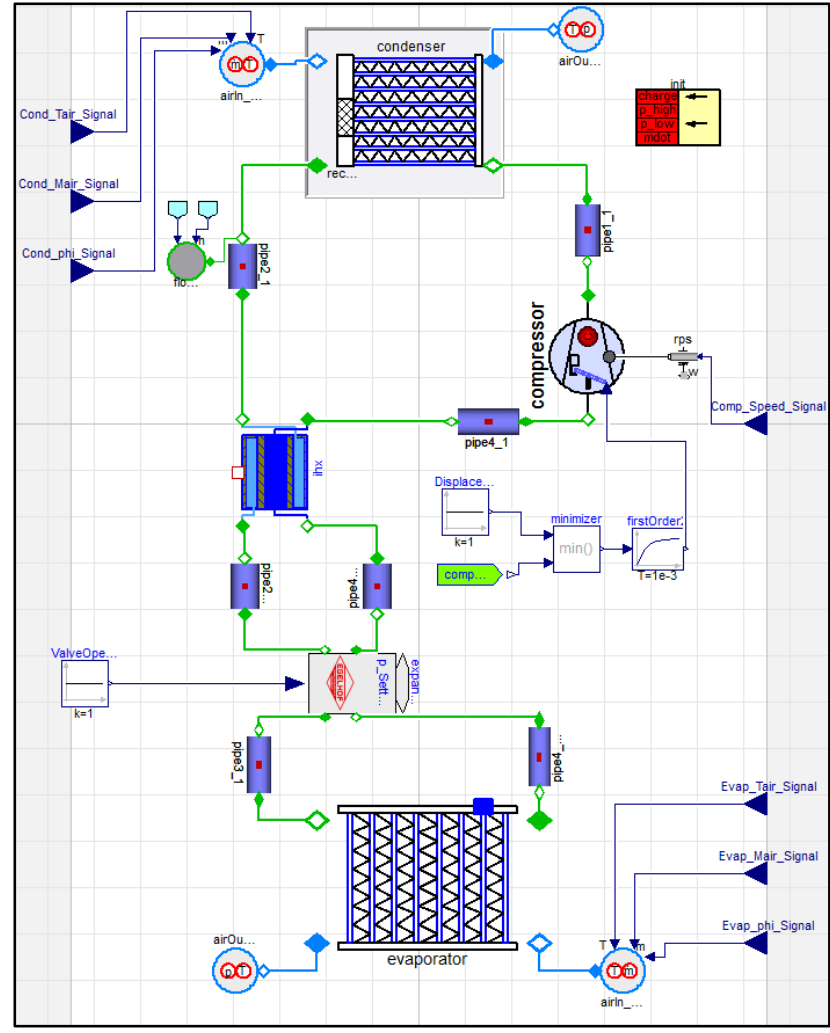

Figure 3. System model developed in Dymola simulation tool.

The validated component models were then integrated to develop the system model as shown in Figure 2. Two variants of the system models were developed; "System A" with engine driven mechanical swashplate compressor and "System B" with battery driven electric scroll compressor; keeping all other components same. The system simulations were carried out in the subsequent stage to evaluate and compare the performance of these two systems.

As previously described (Dermont et al. 2016) the main challenges in simulating the real time conditions are the stop phases, where the mechanical swash plate compressor, during a vehicle stand still at a traffic light, is shut off. In order to mimic the stop phase of the compressor in simulations, the compressor speed was limited to $10 \mathrm{rpm}$. Because of the very low rpm of the compressor, refrigerant mass flow in the system is of the order of $10 \mathrm{E}-4 \mathrm{~kg} / \mathrm{s}$ which results in a zero-mass flow scenario. Flow reversal was observed in some of the components of the system during the stop phase which resulted in lots of numerical problems in the simulation.

Numerical problems in the simulations were caused by the flow reversal that was observed at the outlet of the condenser. This was found to be because of the dynamic enthalpy value that was assigned in the flow source charge, which is connected at the outlet of condenser. The flow source charge is used to ensure fixed quantity of charge inside the system. To fix these numerical problems, the enthalpy input in the flow 
source charge was assigned a constant value. Simulation cases were re-simulated again using Dymola 2017 FD01, where the handling of zero flow simulation was found to be better. It was observed that the simulations were faster and smoother in the new version of Dymola as compared to the previous versions.

\section{Results \& Discussion}

After developing the system models, simulations were done using the MBVT drive cycle for 3 different ambient temperatures and 2 different air mass flows over the evaporator at each ambient temperature. The details of the boundary conditions are as shown below in Table 3.

Table 3. Details of the comparison study for each temperature and air massflow rate

\begin{tabular}{|c|c|c|c|}
\hline \multirow{3}{*}{ MBVT } & $\begin{array}{l}\text { T_ambient } \\
=22^{\circ} \mathrm{C}\end{array}$ & $\begin{array}{l}\text { T_ambient } \\
=29^{\circ} \mathrm{C}\end{array}$ & $\begin{array}{l}\text { T_ambient } \\
=35^{\circ} \mathrm{C}\end{array}$ \\
\hline & {$[\mathrm{kg} / \mathrm{min}]$} & {$[\mathrm{kg} / \mathrm{min}]$} & {$[\mathrm{kg} / \mathrm{min}]$} \\
\hline & 1,5 & 3 & 4 \\
\hline
\end{tabular}

Results are described in the following section.

\subsection{Ambient Temperature $22^{\circ} \mathrm{C}$}

The simulations at $22^{\circ} \mathrm{C}$ ambient temperature and $55 \%$ relative humidity were done with an air mass flow of $1,5 \mathrm{~kg} / \mathrm{min}$ over the evaporator. At $29^{\circ} \mathrm{C}$ ambient (40\% humidity) with a massflow of $2 \mathrm{~kg} / \mathrm{min}$ and at $35^{\circ} \mathrm{C}$ (40\% humidity) with $4 \mathrm{~kg} / \mathrm{min}$. The following simulation results are showing data of the mechanical and electrical system in one graph for each evaluation criterion. The relevant criteria for this paper are:

- Pressure (suction and discharge) [bar]

- Evaporator air outlet temperature $\left[{ }^{\circ} \mathrm{C}\right]$

- Refrigerant Massflow [kg/h]

- Cooling capacity [kW]

- Coefficient of performance (standardized) [-]

In Figure 4, we can see that the suction and discharge pressure reach their aimed ratios for both the systems. For the electrical system both suction \& discharge pressures run more stable, especially for the suction pressure. This fluctuating pressure from the mechanical system can result for example in pulsation which have a negative impact on the acoustics of such a system.

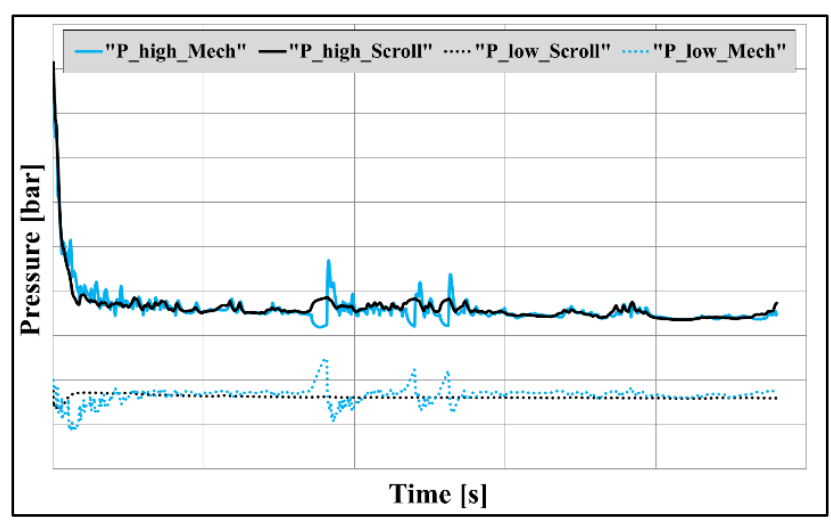

Figure 4. Suction and discharge pressure of both system as a function of time

There are two main aspect visualized in Figure 5. The first one is that the massflow for mechanical system experiences large variations. This is caused by the fact that the compressor is being driven via the belt drive of the ICE. Also in the simulation model, the compressor speed was reduced to a minimum of $10 \mathrm{rpm}$ at stop phases. A complete stand still of the mechanical compressor was not achievable with this Dymola model. This leads us to the second main aspect of Figure 5. Due to the reduction of compressor speed resulting in a reduction of massflow, the air outlet temperature of the evaporator couldn't be kept constant. For longer periods, for example during long phases of traffic signal, it is observed that the temperature increases dramatically. This will result in a massive discomfort in the passenger cabin as compared to the electrical system. The electrical scroll compressor was operated during all stop phases in the drive cycle that results in maintaining the thermal comfort of the passengers.

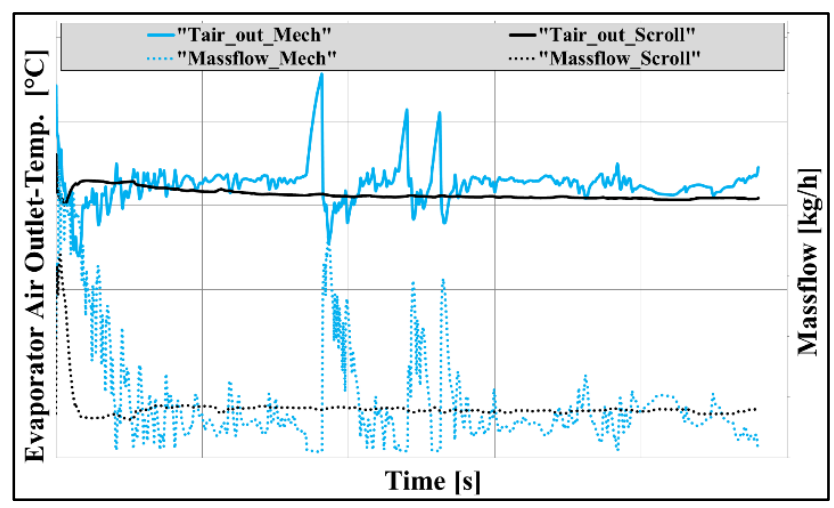

Figure 5. Evaporator air outlet temperature and massflow as a function of time

For the electrical system in general it is evident that it runs more stable compared to the system with the mechanical compressor at $22^{\circ} \mathrm{C}$ ambient temperature. This hypothesis is affirmed in Figure 6. The massive variation of the cooling capacity of the mechanical system is again linked to the stop phases. During the 
stop phase it will decrease because of the reduced compressor speed. Additionally, the temperature of the evaporator increase, as the ambient air at $22^{\circ} \mathrm{C}$ is blown over it. Once the system starts again, the system tries to reach the evaporator air set point temperature of $3^{\circ} \mathrm{C}$.

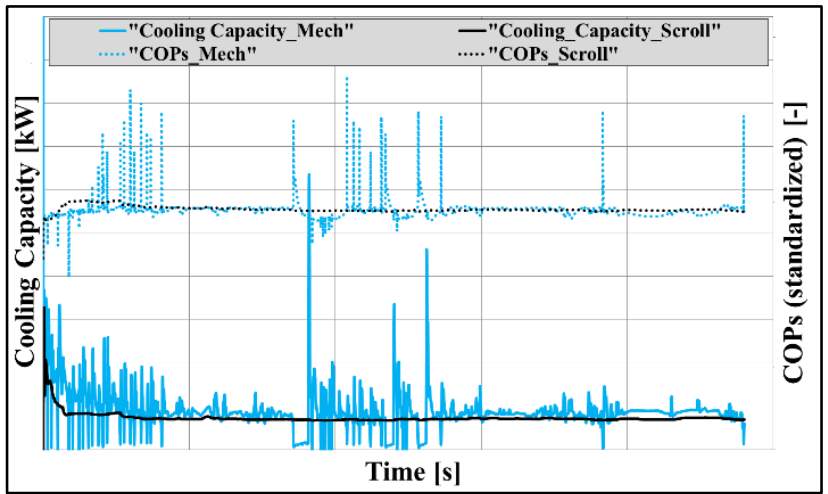

Figure 6. Cooling capacity and COPs as a function of time

Also the variation in COP of the mechanical system can be explained with the stop phases. There it is important to know that mechanical compressors in automotive application have a variable displacement which is controlled via parameters of the refrigeration loop. So once the car starts after a stop phase the loop tries to reach the evaporator air set temperature. The speed of the compressor is fixed to the given profile so the only chance to increase the capacity is to increase the compressor displacement. This is also shown in Figure 4 with the graph of the massflow. There it is noticeable how the massflow is changing due to the changes in the displacement. Because of the design of the variable displacement compressor it is found to be operating in a more efficient mode at lower speed and full displacement. After the set point is achieved the displacement decreases and it runs afterwards in a rather inefficient mode in comparison to the scroll compressor. In Figure 6 the COP is standardized because at stop phases when the mechanical compressor is shut of we still gain the cooling capacity which is stored in the refrigerant loop. But in the meantime you lose thermal comfort in the vehicle cabin so it is needed to take this also into consideration in calculation of the COP. So the factor $\varepsilon$ is introduced for calculating COPs. Its graph is plotted for the air outlet temperature over the evaporator in Figure 7.

$$
\text { COPS }=\text { COP } \times \varepsilon
$$

where,

$$
\varepsilon=\frac{\vartheta_{\text {evap_set }}}{\left|\vartheta_{\text {evap_out }}-\vartheta_{\text {evap }_{\text {set }}}\right|+\vartheta_{\text {evap_set }}}
$$

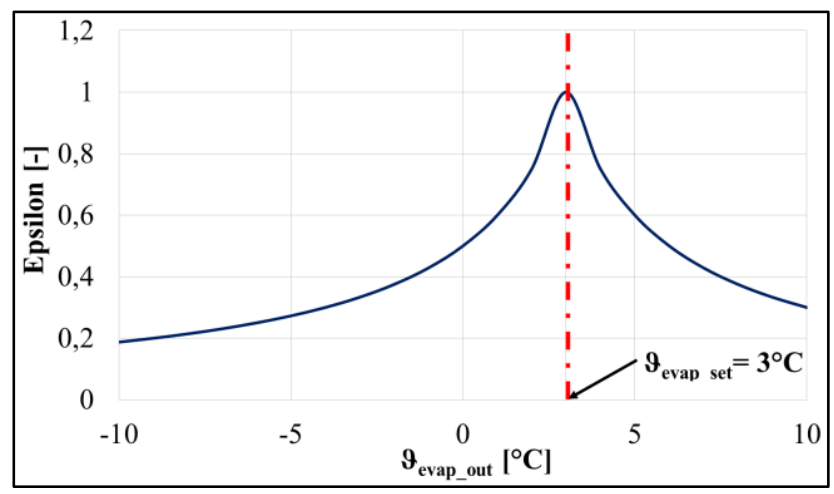

Figure 7. Correction factor $(\varepsilon)$ for each temperature of the air at the evaporator outlet

\subsection{Ambient Temperature $29^{\circ} \mathrm{C}$}

The following graphs for $29^{\circ} \mathrm{C}$ ambient are pretty similar to those of $22^{\circ} \mathrm{C}$ ambient. In Figure 8 we see that both systems attaining the same high pressure level and due to the constant speed of the electrical compressor the suctions pressure is in stable conditions.

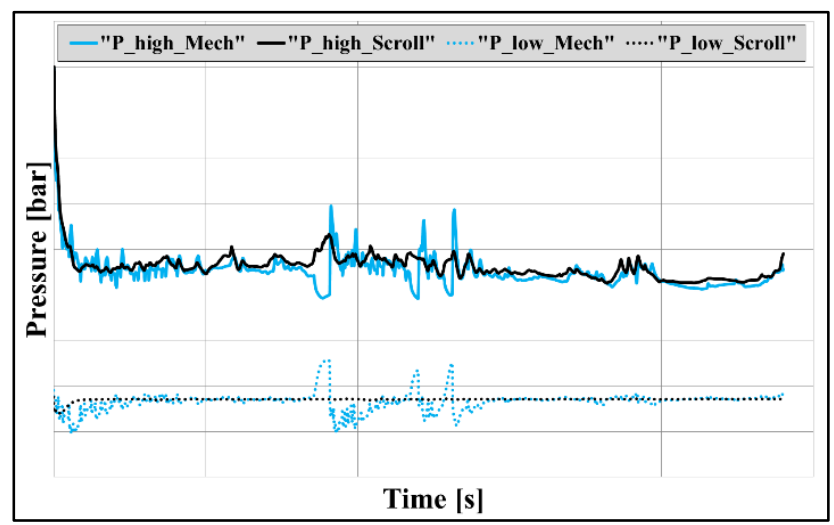

Figure 8. Suction and discharge pressure of both system as a function of time

In Figure 9 the advantages of an electrical system are evident. Constant refrigerant massflow and evaporator air exit temperatures are observed for most part of the system operation. Thermal comfort in the cabin is also maintained for most part of the drive cycle. 


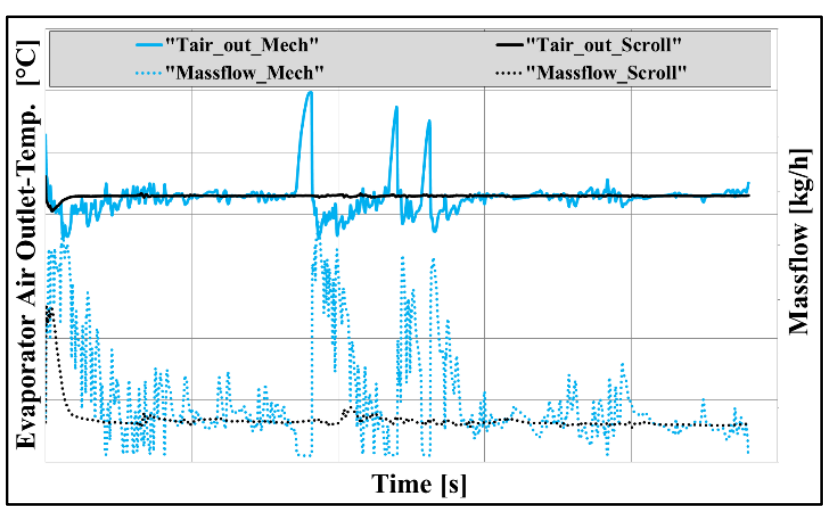

Figure 9. Evaporator air outlet temperature and massflow as a function of time

By visual comparison the system with an electrical compressor operates with a better COPs for most part of the drive cycle. The large peaks for the system with mechanical compressor are due to the stored cooling capacity in the system. Additionally, it is observed from Figure 8 that the high pressure for the mechanical system decreases during the stop phases.

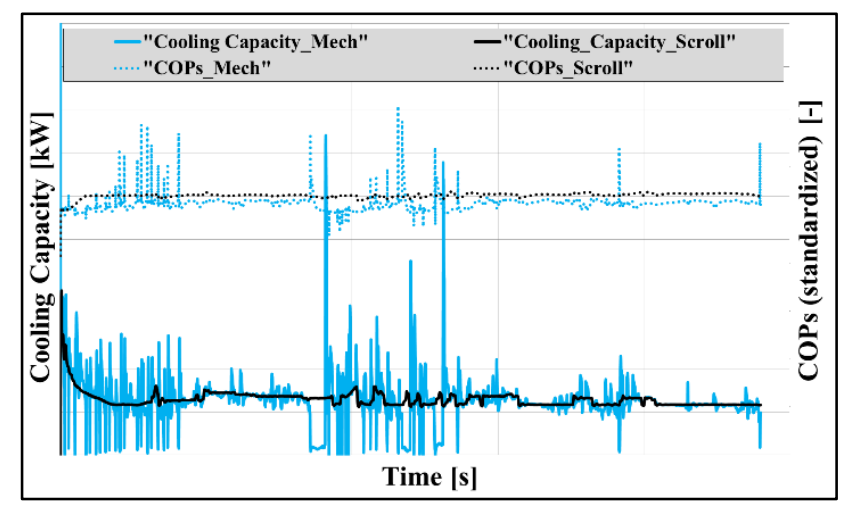

Figure 10. Cooling capacity and COP as a function of time

In order to compare both systems in terms of efficiency we compare the classic COP without standardization regarding cabin comfort:

$$
\begin{aligned}
\overline{C O P_{e}} & =\frac{\sum_{n=1}^{t} \operatorname{COP}_{e_{n}}}{t} ; \overline{C O P s_{m}}=\frac{\sum_{n=1}^{t} \operatorname{COP}_{m_{n}}}{t} \\
\rightarrow C O P_{v} & =\frac{\overline{C O P_{e}}}{\overline{C O P_{m}}}=1,2851 \approx 128,5 \%
\end{aligned}
$$

So even under severe conditions the electrical compressor system runs at $29^{\circ} \mathrm{C}$ in a higher COP by $28,5 \%$ compared to the mechanical compressor system. The work that is needed over the driving cycle for the mechanical conferred to the electrical is higher by $57 \%$. Although there is just an overall advantage of $28 \%$ the difference is with variation of the cooling capacity.

\subsection{Ambient Temperature $35^{\circ} \mathrm{C}$}

In the end the simulations where done at an ambient temperature of $35^{\circ} \mathrm{C}$. In statistics this might be the most severe temperature for Germany for example. But in southern parts of Europe and for example in the western region of the United States of America these temperatures occur more often. It is easy to detect that now both systems operate at the upper end of their capacities. In Figure 11 the suction pressure stays in the same regions except during the stop phases, but the high pressure differs a lot. This can be explained to the different compressor types. As previously described the mechanical compressor is a piston type and the electrical is a scroll one.

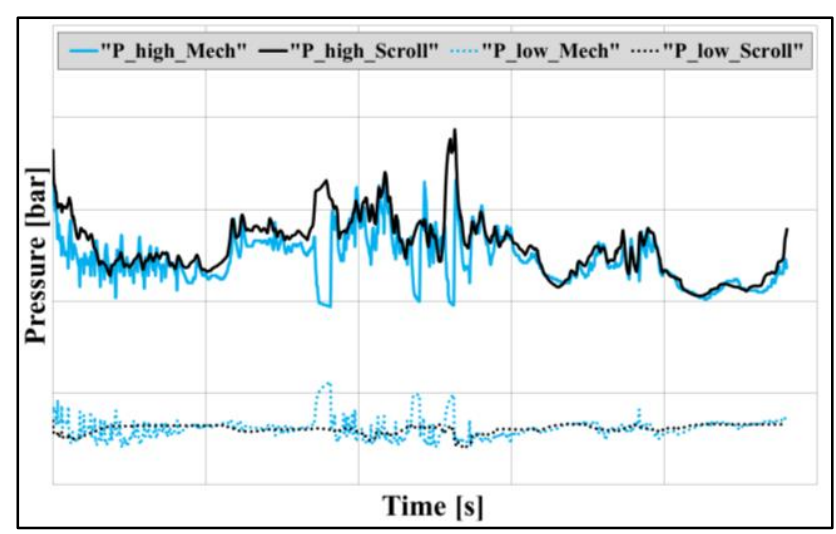

Figure 11. Suction and discharge pressure of both system as a function of time

Although the exciting air temperature over the evaporator is almost kept constant for the electrical system you can easily see by analyzing the plotted massflow that the compressor is also varying the speed. The massive differing shows that even if the scroll compressor is independent of the belt drive of the ICE it regulates dynamically for this high load case.

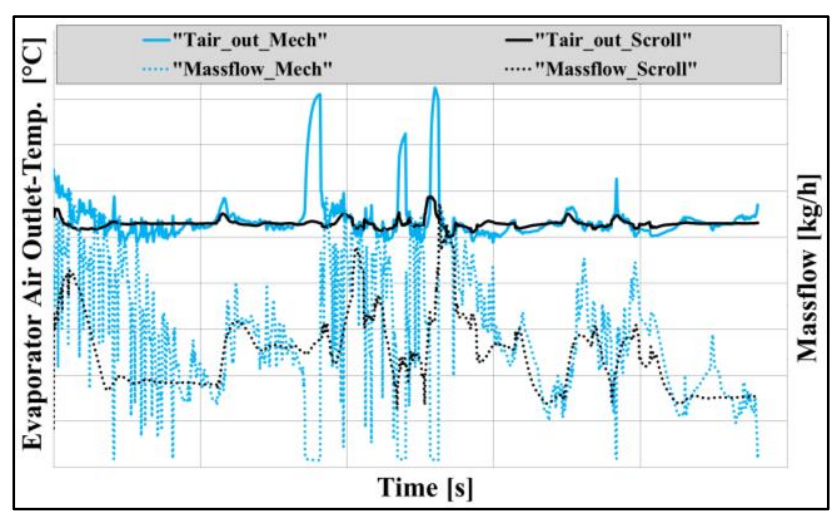

Figure 12. Evaporator air outlet temperature and massflow as a function of time

As a last the COPs in Figure 13 interestingly are no longer higher for the electrical system. This is also due 
to the compression technique of the mechanical compressor. Piston type compressors have an optimum operation ratio at almost full stroke with $100 \%$ displacement. The average displacement over this driving cycle for the mechanical system is at $50 \%$.

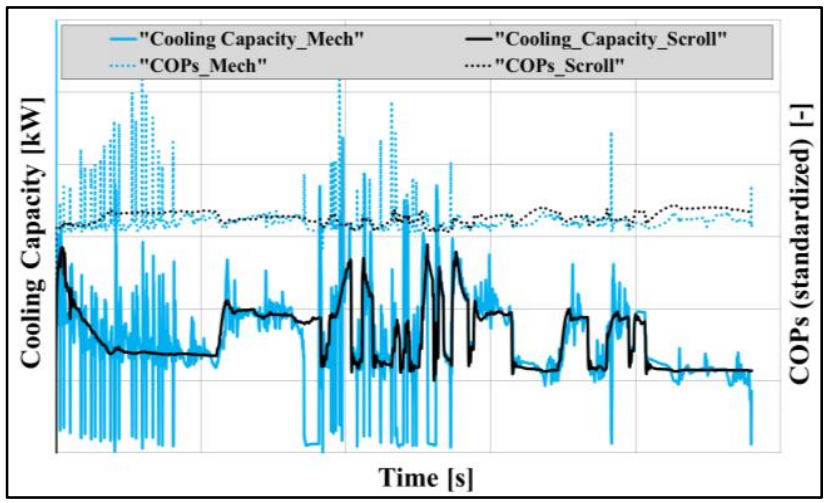

Figure 13. Cooling capacity and COPs as a function of time

Simulations plots are described for one evaporator air massflow rate at each ambient temperatures. All the plots aren't added to this paper but they do show similar behavior in general. The conclusion all in all stays the same.

\section{Conclusion}

For future investigation simulation tools such as Dymola will be mainly used for efficiency analysis and system optimizing operations. The comparative study outlined this strategy and justified this procedure. This simulation will be moreover expand in an even wider temperature range to complete the virtual behavior of an automotive A/C-loop. Especially transient simulations will become more and more sufficient. By simulating a mechanical compressor at all ambient temperatures and even an electrical at severe conditions the changes in the massflow are tremendously. By simulating just steady state conditions you can't visualize those changes that are also important for NVH (Noise Vibration and Harshness) analyses and cabin comfort for the customer. The shut-off phases of the mechanical system are the main issue as stated in chapter 3. For this point of view we could show that the system driven with an electrical scroll compressor has $20 \%$ higher COPs at $29^{\circ} \mathrm{C}$ than a system with a mechanical (belt driven) compressor. In terms of increasing the system efficiency, the hybridization of passenger cars is also a big chance for the thermal management of the cabin and powertrain. A validation of the simulation model is of course applicable and will be done as a next step.

\section{Acknowledgements}

The authors would like to thank and gratefully acknowledge the support received from RD/KIT and RD I/CCS departments at Daimler AG \& MBRDI respectively.

\section{Publication bibliography}

Carpetis, C. (2000): Globale Umweltvorteile bei Nutzung von Elektroantrieben mit Brennstoffzellen und/oder Batterien im Vergleich zu Antrieben mit Verbrennungsmotor. Edited by Deutsches Zentrum für Luft und Raumfahrt e.V. Institut für Technische Thermodynamik. Stuttgart (STB-Bericht, 22), checked on 10/12/2016.

Coppin, Oliver; Potteau, Sébastien (2015): 48-V-HybridSystemarchitektur zur Reduzierung der CO2-Emissionen. In ATZ elektronik 10 (02).

Dermont, Pieter; Limperich, Dirk; Windahl, Johan; Prölss, Katrin; Kübler, Carsten (2016): Advances of Zero Flow Simulation of Air Conditioning Systems using Modelica. In : Deployment of high-fidelity vehicle models for accurate realtime simulation, 2011-02-05: Linköping University Electronic Press (Linköping Electronic Conference Proceedings), pp. 139-144.

Europäische Union (6/14/2006): Richtlinie 2006/40/EG des Europäischen Parlaments und des Rates vom 17. Mai 2006 über Emissionen aus Klimaanlagen in Kraftfahrzeugen und zur Änderung der Richtlinie 70/156/EWG des Rates. 2006/40/EG, revised L161/12.

Lemke, Nicholas; Mildenberger, Julia; Graz, Martin (2011): Unterstützung der Markteinführung von Pkw-Klimaanlagen mit dem Kältemittel CO2 (R744). Prüfstandsmessungen und Praxistest. Im Auftrag des Umweltbundesamtes. Edited by Umweltbundesamt. Dessau-Roßlau (Texte, 64). Available online at http://www.uba.de/uba-info-medien/4184.html, checked on $6 / 25 / 2015$.

Slattery, B. E.; Edrisy, A.; Perry, T. (2010): Investigation of wear induced surface and subsurface deformation in a linerless Al-Si engine. In Wear 269 (3-4), pp. 298-309. DOI: 10.1016/j.wear.2010.04.012.

\section{Nomenclature}
A/C Air Conditioning
BEV Battery Electric Vehicle
COP Coefficient of Performance
COPs Coefficient of Performance standardized
GWP Global Warming Potential
ICE Internal Combustion Engine
IHX Internal Heat Exchanger
MAC Mobile Air Conditioning
MBVT Special Daimler Driving Cycle
MHEV Micro Hybrid Electric Vehicle 


$\begin{array}{ll}\text { NVH } & \text { Noise Vibrations and Harshnes } \\ \text { PHEV } & \text { Plug-In Hybrid Electric Vehicle } \\ \text { RPM } & \text { Rounding Per Minute } \\ \text { n } & \text { Compressor speed } \\ \pi & \text { Compressor pressure ratio } \\ \text { d } & \text { Relative displacement } \\ \text { mdot } & \text { Refrigerant mass flow rate through compressor } \\ \text { P } & \text { Compressor power consumption }\end{array}$

